\title{
Adesão e aderência à prática do boxe em uma academia do Sul de Minas Gerais
}

\author{
Accession and adherence to the practice of boxing in a gym in the south of Minas Gerais \\ Adhesión and adherencia a la práctica del boxeo en un gimnasio del sur de Minas Gerais
}

Recebido: 19/04/2021 | Revisado: 26/04/2021 | Aceito: 01/05/2021 | Publicado: 15/05/2021

Uilma Libarino

ORCID: https://orcid.org/0000-0001-7500-5656 Universidade Federal de Lavras, Brasil

E-mail: ulsilva@estudante.ufla.br

Álex Sousa Pereira

ORCID: https://orcid.org/0000-0003-2617-2065

Universidade Estadual de Campinas, Brasil

E-mail: alexjhowsp@hotmail.com

Kleber Tuxen Carneiro

ORCID: https://orcid.org/0000-0003-0826-6172 Universidade Federal de Lavras, Brasil

E-mail: kleber.azevedo@ufla.br

Alessandro Teodoro Bruzi

ORCID: https://orcid.org/0000-0002-0018-0537 Universidade Federal de Lavras, Brasil E-mail: bruzi@ufla.br

Fábio Pinto Gonçalves dos Reis

ORCID: https://orcid.org/0000-0003-4797-5895 Universidade Federal de Lavras, Brasil E-mail: fabioreis@ufla.br

\begin{abstract}
Resumo
Atualmente, o boxe apresenta-se como uma forma moderna de prática corporal no interior das academias, com o acréscimo de elementos da ginástica e do treinamento funcional. Nesse contexto, nossa pesquisa teve como objetivo compreender quais são os fatores relacionados à adesão e aderência dessa prática corporal em uma academia do Sul de Minas Gerais. Para tanto, realizou-se uma pesquisa assentada nos pressupostos qualitativos sob um desenho descritivo, valendo-se de entrevista semiestruturada junto a dez praticantes. Concluímos que vários aspectos estão relacionados à adesão e a aderência à prática de boxe, porém, alguns se destacaram nas narrativas. No que se refere à adesão, os motivos de maior destaque foram: a busca pela prática para promoção da saúde; a disponibilidade de horários das aulas; à paixão pelo boxe; e o aprimoramento da técnica de luta para variados fins, bem como, o incentivo da família e dos amigos. Já, em relação à aderência, os motivos mais mencionados foram: a motivação e a variabilidade de treinamento; a disponibilidade de horários de aulas e as interações sociais no interior da academia que, no caso específico, contribuem para a construção de uma identidade coletiva no sentido do pertencimento ao grupo.
\end{abstract}

Palavras-chave: Boxe; Adesão; Aderência.

\begin{abstract}
Currently, boxing presents itself as a modern form of body practice inside the gyms, with the addition of elements of gymnastics and functional training. This constitution of the practice of boxing has attracted many supporters, including women, with the most different purposes. In this context, our research aimed to understand what are the factors related to adherence and adherence to this body practice in a gym in the south of Minas Gerais. To this end, a research was carried out based on qualitative assumptions under a descriptive design, using a semi-structured interview with ten practitioners. We conclude that several aspects are related to adherence and adherence to the practice of boxing, however, some stood out in the narratives. With regard to adherence, the most prominent reasons were: the search for practice for health promotion; the availability of class schedules; the passion for boxing; and the improvement of the fighting technique for various purposes, as well as the encouragement of family and friends. In relation to adherence, the most mentioned reasons were: motivation and training variability; the availability of class schedules and social interactions within the academy that, in the specific case, contribute to the construction of a collective identity in the sense of belonging to the group.
\end{abstract}

Keywords: Boxing; Accession; Adherence.

\section{Resumen}

Actualmente, el boxeo se presenta como una forma moderna de práctica corporal dentro de los gimnasios, con la incorporación de elementos de gimnasia y entrenamiento funcional. Esta constitución de la práctica del boxeo ha 
atraído a muchos seguidores, incluidas mujeres, con los más diferentes propósitos. En este contexto, nuestra investigación tuvo como objetivo comprender cuáles son los factores relacionados con la adherencia y adherencia de esta práctica corporal en un gimnasio del sur de Minas Gerais. Para ello, se realizó una investigación basada en supuestos cualitativos bajo un diseño descriptivo, utilizando una entrevista semiestructurada con diez profesionales. Concluimos que varios aspectos están relacionados con la adherencia y adherencia a la práctica del boxeo, sin embargo, algunos se destacaron en las narrativas. En cuanto a la adherencia, las razones más destacadas fueron: la búsqueda de prácticas para la promoción de la salud; la disponibilidad de horarios de clases; la pasión por el boxeo; y el perfeccionamiento de la técnica de lucha para diversos fines, así como el estímulo de familiares y amigos. En relación a la adherencia, las razones más mencionadas fueron: motivación y variabilidad del entrenamiento; la disponibilidad de horarios de clases e interacciones sociales dentro de la academia que, en el caso específico, contribuyan a la construcción de una identidad colectiva en el sentido de pertenencia al grupo.

Palabras clave: Boxeo; Adhesión; Adherencia.

\section{Introdução}

Historicamente, a palavra boxe se origina do verbo inglês to box, cuja tradução, em linhas gerais, seria: bater, combater e golpear com os punhos e mãos. Há, além disso, o emprego do termo em latim pugillus, muito utilizado para nomear a prática dessa modalidade, refere-se às ações contra oponentes utilizando os punhos fechados. Convém salientar que foi a partir dessas denominações que estudiosos da área definiram o pugillatus (em português, pugilato) na qualidade de terminologia mais adequada para descrever a origem do boxe, desde sua existência como atividade social e esportiva (Melo \& Vaz, 2006).

No Brasil a história do boxe teve início no fim do século XIX com a vinda de imigrantes europeus, época em que ainda era considerada uma prática corporal marginalizada (Melo \& Vaz, 2006). Por se tratar de uma prática corporal (historicamente situada), corresponde ao contexto cultural no qual se insere, a despeito de ser uma modalidade de luta - no sentido originário -, sua apropriação pode receber diferentes conotações, quiçá isso explique, ao menos em partes, à ascensão e aceitação cuja atividade tem mobilizado, por efeito atraído cada vez mais adeptos/as, nos dias atuais.

Soma-se a isso a ascendência das "demandas da silueta", um conceito postulado por Bronzatto et al. (2018), no qual o estado de reificação dos corpos subjuga às experiências corporais reduzindo-as a um padrão estético idealizado, na prática, depauperando suas expressões, inclusive afetivas. Trata-se, em outras palavras, do culto ao corpo, já que ele (lê-se o corpo) se converteu num instrumento de poder, notadamente em razão dos signos da beleza, da virilidade e da juventude. A esse respeito adverte Costa (2004), "se o interesse pelo corpo começa e termina nele, caímos na corpolatria, forma de ascese humanamente pobre e socialmente fútil” (p. 19).

Tem-se também, à busca pelas modalidades de lutas como mecanismo de promoção e manutenção da saúde, observando nessa prática corporal um caminho para o bem-estar, isto é, uma espécie de "equilíbrio existencial” (Reis, et al. 2020). Cientes dessa conjuntura, na qual há diferentes perspectivas pelas quais se inscrevem o "despertar" pelo boxe, resolveu-se empreender uma investigação científica, cujo fito central consistiu em analisar os motivos pelos quais os alunos e alunas de uma academia de boxe - situada em uma cidade ao Sul de Minas Gerais - iniciaram essa vivência, de igual modo perscrutar as razões que conduzem à permanência na mesma.

O espaço investigado oferta (exclusivamente) aulas de boxe, contando com a participação efetiva de 250 alunos/as, de diferentes gêneros e idades variadas. Após um período de observação - sob a acepção de participação passiva - in loco, constatou-se a existência de aspirações distintas, no que concerne à prática corporal, tanto em relação ao arquétipo existente sobre a luta quanto aos ideários relativos à saúde e as "demandas da silueta" (Ludke \& André, 1986; Sampieri et al., 2013). Com efeito, elaborou-se a seguinte indagação: quais são os principais fatores que explicam a adesão e a aderência desses alunos/as em relação à prática do boxe?

Na tentativa de compreender o processo de iniciação e engajamento em uma prática de exercícios, Telles (2016) anota que em princípio há a adesão; subsequente tem-se a aderência a qual se refere à continuidade ou permanência na mesma. 
Complementa a autora explicando se tratar de conceitos intimamente ligados e interdependentes, pois não há aderência, sem que haja inicialmente adesão.

Nessa esteira de reflexão, Saba (2001) indica que os principais fatores fomentadores da adesão em relação à determinada atividade física são: o controle de peso corporal; redução à propensão às doenças cardiovasculares, ao estresse e à depressão; satisfação pessoal; melhora da autoestima; e à socialização. Para o autor supracitado, após o início da atividade o obstáculo mais proeminente refere-se à aderência ao exercício, dado:

[...] que consiste em um conjunto de questões, sejam elas ambientais (influência médica; apoio social da família, amigos, professor; clima; custo; esforço percebido; qualidades do líder, dentre outros) ou pessoais (sobrepeso; situação econômica; falta de tempo; automotivação; satisfação no exercício; dieta etc.), que possibilitam a manutenção dessas atividades por um período longo de tempo (Saba, 2001, p.113).

Adentrando o domínio mais específico sobre o qual versa nossa investigação, o estudo de Silva (2015) - realizado somente com mulheres - concluiu que os motivos mais relevantes para a adesão ao boxe dizem respeito à localização da academia e a sociabilidade no seu interior. Já em relação à aderência fez-se referência ao alto gasto calórico - sob os ideais do culto ao corpo - e o dinamismo presente nessa modalidade de combate. Convém destacar, além do mais, à questão do ambiente e a diminuição e o controle do estresse, figurando por sua vez, como elementos impulsionadores, quer para a adesão, quer em relação à aderência à prática do boxe.

Em nosso entender, há outras razões pelas quais as pessoas se inserem e se conservam no interior dessa prática corporal, por efeito procuram o espaço investigado. À vista disso empreendemos este estudo, sob uma perspectiva (científica, epistemológica e didática) mais abrangente, alvitrando expandir "as margens” de compreensão do fenômeno em análise. Isso equivale a dizer que partimos do pressuposto da existência de motivos mais amplos - afora às "fronteiras biológicas" e situacionais - para a iniciação e a permanência dos/as alunos/as na academia investigada. Soma-se a isso, a verificação do número "tímido" de literatura científica dedicada ao entendimento da adesão e aderência ao boxe, cujas análises sobrepujem o espectro relativo ao campo da saúde, fato constatado por ocasião do cotejamento inicial realizado.

Sendo assim, nosso empreendimento científico se justifica na medida em que contribui para compreensão das variáveis que compreendem essa prática corporal, do mesmo modo em que lança rebento aos profissionais da área, na tentativa de encontrarem alternativas formativas para difundir a modalidade - aprimorando questões objetivas, subjetivas e organizacionais -, a fim de que promovam à adesão e aderência dessa modalidade de luta (Martins, 2017).

Conjecturamos, nesse sentido que, no plano da adesão, existam dois fatores preponderantes: a promoção e manutenção da saúde e a dimensão estética - impulsionada pelas "demandas da silueta", sob a ingerência da "corpolatria" (Bronzatto et al. 2018; Costa, 2004). Já em relação à aderência, nossas hipóteses preliminares compreendem três fatores, quais sejam: o primeiro refere-se à esfera didática, mais especificamente à metodologia empregada nas aulas, ou seja, a proposta de coligar os elementos do boxe e o treinamento funcional suscita uma prática mais dinâmica e diversificada, ou menos enfadonha, por assim dizer. O segundo diz respeito à rede de sociabilidades desenvolvida no interior da academia, nessa direção, tem-se um espaço de encontros e desenvolvimento de vínculos afetivos, diferindo de outros ambientes nos quais ocorrem exercícios de modo individualizado, em outros dizeres, com restritas interações sociais. E o terceiro concerne às condições objetivas de oferta para vivência, em especial à disponibilidade de horários e realização das aulas.

A esse respeito, Santos e Knijnik (2006) comentam a falta de tempo normalmente decorrente de uma jornada excessiva de trabalho, somada às obrigações familiares e dificuldade na administração da vida pessoal. Figurando, portanto, na condição de principais aspectos cujos efeitos obliteram e conduzem ao abandono da prática de exercício. A seguir detalhar-nos-emos os aspectos metodológicos do estudo. 


\section{Metodologia}

Tratou-se de uma pesquisa assentada sob os pressupostos qualitativos, uma vez que tal modalidade nos confere a possibilidade de observar/compreender os valores, crenças, hábitos, atitudes, representações, opiniões sobre fatos e processos particulares e específicos dos indivíduos e grupos em que estão inseridos (Sampieri et al., 2013).

Ao mencionar os benefícios de uma pesquisa qualitativa, Sampieri et al. (2013, p.102) explanam se tratar de investigações cujo objetivo pretende analisar informações de maneiras independentes "ou [mesmo] conjunta sobre os conceitos ou as variáveis a que se referem. Logo, podem integrar as medições ou informação de cada uma das variáveis ou conceitos para dizer como é e como se manifesta o fenômeno de interesse".

Em termos de desenho - ou abordagem -, optou-se pelo enfoque descritivo. Corresponde a uma perspectiva na qual se busca "especificar as propriedades, as características e os perfis de pessoas, grupos, comunidades, processos, objetos ou qualquer outro que se submeta a uma análise (Sampieri et al., 2013, p. 102)”. Em outras palavras, corresponde ao delineamento de investigações cujo objetivo pretende explorar contextos e situações, sob outros pontos de vista do fenômeno perscrutado.

$\mathrm{Na}$ qualidade de recurso para produção do material empírico, realizamos entrevistas semiestruturadas junto aos praticantes de boxe, vinculados ao espaço investigado. De acordo com Ludke e André (1986), a entrevista semiestruturada consiste em um instrumento do qual se vale para a obtenção das informações. Cabe salientar que esse procedimento indagador figura como instrumento básico para coleta de dados em estudos sob orientação qualitativa. Não incorreríamos em nenhuma hipérbole afirmar que a entrevista representa o apogeu de uma pesquisa assentada segundo os pressupostos qualitativos (Ludke e André, 1986).

Lembrando, além disso, o fato de que à abertura das entrevistas semiestruturadas podem fomentar novas proposições a partir das respostas dos/as informantes, de maneira a ampliar o universo dos dados, com efeito, expandir o alcance da investigação e de seus resultados. Para tanto, elaborou-se o seguinte roteiro:

Quadro 1: Roteiro para a entrevista com os/as alunos/as.

Por que você escolheu o boxe?

Como você conheceu a academia?

Qual o seu objetivo ao treinar o boxe?

Quais as atividades que você mais gosta? Por quê?

Sobre as aulas, o que você acha da forma com que são organizadas e conduzidas? Como é o acompanhamento do professor?

De que maneira a disponibilidade de horários atende a conciliação da atividade com a vida cotidiana?

Como é a relação entre os praticantes e as interações que ocorrem dentro da academia?

Fonte: Elaboração própria dos pesquisadores.

Com base nesse roteiro, entrevistou-se 10 pessoas, de ambos os sexos, sendo a letra M correspondente ao sexo masculino e a F para o feminino, seguida de uma sequência numérica. A faixa etária variou entre 22 e 44 anos. Na qualidade de critério principal de inclusão do/a participante, exigia-se que todos/as os/as pesquisados/as deveriam praticar boxe na academia há mais de seis meses. Trata-se de um critério alinhado ao entendimento de Martins (2017), segundo o qual, seis meses, corresponder-se-ia ao tempo o mínimo no qual um indivíduo entre na fase de manutenção, com isso torne a 
prática de se exercitar em um hábito.

A seguir, apresentamos o perfil dos sujeitos pesquisados (Quadro 2):

Quadro 2: Informações dos alunos entrevistados.

\begin{tabular}{|c|c|c|}
\hline SUJEITO & IDADE & TEMPO DE PRÁTICA \\
\hline M1 & 32 anos & 3 anos \\
\hline M2 & 39 anos & 2 anos e meio \\
\hline M3 & 42 anos & 5 anos e meio \\
\hline M4 & 22 anos & 6 anos \\
\hline M5 & 35 anos & 4 anos \\
\hline FI & 35 anos & 2 anos \\
\hline F2 & 26 anos & 1 ano e meio \\
\hline F3 & 44 anos & 1 ano \\
\hline F4 & 36 anos & 24 anos \\
\hline F5 &
\end{tabular}

Fonte: Elaboração própria dos pesquisadores.

Cabe destacar que a investigação em tela foi desenvolvida de acordo com as normativas estabelecidas na Resolução CNS n 466/2012 a qual regulamenta a dimensão ética de pesquisas envolvendo seres humanos, tendo sido escrutinada pelo Comitê de Ética e Pesquisa com Seres Humanos de uma universidade pública mineira. Em razão disso houve aquiescência da participação voluntária e assinatura do Termo de Consentimento Livre e Esclarecido (TCLE).

Com o objetivo de facilitar a transcrição e organização das informações, todas as entrevistas foram gravadas, em seguida transcritas e posteriormente textualizadas. Para categorizar, analisar e interpretar as informações se empregou o método de triangulação dos dados. A triangulação diz respeito à conjunção de metodologias diferentes para analisar o mesmo fenômeno, de modo a consolidar a construção de conjecturas (Ludke e André, 1986).

Consoante às autoras supracitadas, refere-se a uma alternativa qualitativa para a validação de uma pesquisa, à medida que permite o emprego de múltiplos métodos de pesquisa, com efeito, assegura a compreensão mais profunda do fenômeno investigado. No interior da triangulação dos dados, trabalha-se com categorias a serem investigadas que podem ser, ou não predefinidas, a depender do interesse, ou contingência do/da pesquisador/a em relação ao mote investigado. Se optar por definições prévias de categorias, após a coleta de dados estas classificações poderão ser revistas, ou ainda (re)formuladas nesta etapa da pesquisa e não previamente.

Em termos analíticos, deve-se no primeiro processo interpretativo realizar "uma valorização fenomênica e técnica dos dados primários, em si mesmos e à exaustão" (Gomes et al., 2010, p. 185). Empós, as narrativas orais são "contextualizadas, criticadas, comparadas e trianguladas" (Gomes et al., 2010, p. 185). Cabe destacar que a organização do primeiro processo interpretativo ocorre mediante três etapas: 1) preparação e reunião dos dados; 2) a avaliação da qualidade e, por último, 3) a elaboração de categorias de análise. Muito bem, a próxima seção dedica-se a expor os agrupamentos e análises realizadas.

\section{Resultados e Discussão}

\subsection{Narrativas relacionadas à adesão à prática do boxe}

Antes de adentrarmos, detidamente, à interpretação dos dados coletados, convém destacar que, para Saba (2001), a adesão à prática do exercício é uma tarefa difícil, constituída sistematicamente por quatro fases específicas, a saber: adoção, manutenção, desligamento e retomada da atividade. Vejamos doravante a descrição das mesmas. 
1 A fase da adoção caracteriza-se pela relação com o bem-estar e pela crença nos benefícios à saúde; 2 na fase da manutenção, geralmente os indivíduos estão mais motivados e traçam suas próprias metas. O autor aponta também que, nessa fase, percebe se o apoio familiar e que a adesão está relacionada com bem-estar e prazer; $\mathbf{3}$ a fase de desligamento está relacionada com fatores como falta de tempo, motivação, questões situacionais, e ocorre mais em pessoas que tem em seu histórico o sedentarismo e baixa capacidade motora ou física; 4 a fase da retomada da atividade geralmente ocorre quando o sujeito consegue administrar melhor o seu tempo, sente mais autoconfiança e passa a estabelecer metas mais flexíveis (Saba, 2001, p.113).

Segundo o autor em questão, a ocupação laboral do/a aluno/a poderá interferir na adesão à prática de exercício, haja vista, por exemplo, um trabalhador cuja atividade profissional exija demasiado esforço corporal ao longo do seu dia, desgastando-se fisicamente. Trata-se de um entendimento análogo ao de Santos e Knijnik (2006), conforme expusemos antes. Nesse sentido, outros fatores aparecem como sendo facilitadores ou não à adesão. Dentre eles destacam-se: a automotivação; a saúde; os fatores geográficos (morar próximo ou não ao local de prática); e os relacionados às condições objetivas, como o tempo disponível e custo-benefício da mesma.

Os excertos a seguir, referem-se às respostas dos/as depoentes em relação à primeira pergunta da entrevista.

Quadro 3: Por que você escolheu o Boxe?

\begin{tabular}{|c|l|}
\hline M1 & "O boxe era uma paixão de infância, logo, quando surgiu uma oportunidade de fazer, eu comecei." \\
\hline M2 & $\begin{array}{l}\text { "Porque o boxe ajuda muito no condicionamento físico. E também pela disponibilidade de } \\
\text { horários." }\end{array}$ \\
\hline M3 & $\begin{array}{l}\text { "Eu escolhi o boxe porque ele ajuda a mente, a ter mais equilíbrio, reduzir o estresse e por outras } \\
\text { questões de saúde também." }\end{array}$ \\
\hline M4 & $\begin{array}{l}\text { "Eu sempre gostei de lutas, a minha paixão veio dos filmes e como eu nunca fui muito habilidoso } \\
\text { com as pernas, procurei o boxe que faz uso somente dos punhos, gostei e estou até hoje." }\end{array}$ \\
\hline M5 & "Eu fazia taekwondo, mas mudei para o boxe por causa da disponibilidade de horários." \\
\hline FI & "Escolhi o boxe por ser uma atividade prazerosa." \\
\hline F2 & "Comecei a fazer para sair do sedentarismo." \\
\hline F3 & \begin{tabular}{l} 
"Eu entrei no boxe para acompanhar meu filho que é muito tímido" \\
\hline F4
\end{tabular} $\begin{array}{l}\text { "Porque eu sempre tive vontade de aprender a lutar, por uma questão de defesa pessoal e por ser } \\
\text { perto da minha casa." }\end{array}$ \\
\hline F5 & $\begin{array}{l}\text { "Foi principalmente para emagrecer, manter a saúde e porque aqui tem muitos horários } \\
\text { disponíveis." }\end{array}$ \\
\hline
\end{tabular}

Fonte: Elaboração própria dos pesquisadores.

Ao analisar as respostas relativas à primeira questão, observam-se vários fatores aludidos, com destaque à redução do estresse, o emagrecimento, a satisfação pessoal, a utilização da modalidade na condição de defesa pessoal e a comodidade por ser próximo de casa. Contudo, três fatores chamam atenção por terem sido enfatizados mais de uma vez.

A paixão pelo boxe consiste no primeiro - a propósito, a relação entre paixão e os esportes individuais foi o mote central do estudo desenvolvido por Caruzzo, et al. (2020) - . Com base nas respostas, pode-se inferir que a popularização dessa prática corporal exerça atuação direta para sua adesão, notadamente em razão de sua presença em filmes, competições televisionadas ou pelos ídolos que se tornaram referências, principalmente para o gênero masculino. Quanto a isso, Melo e Vaz (2006) ao analisarem a relação entre o cinema e o boxe, destacam os elementos que compreendem a construção da masculinidade, examinando filmes com essa temática e suas implicações sobre o comportamento de praticantes. Os autores enfatizam aspectos como: a coragem, a resistência, a virilidade masculina e a ascensão do lutador como impulsionadores do desejo à prática do boxe. 
Alinhados a essa sequência de reflexão, Pereira et al. (2021) admitem a presença dos artefatos culturais - se empregados de forma responsável e a luz de um exame crítico - para propagação e ensino das lutas/artes marciais.

A disponibilidade de horários refere-se a outro fator. Em três, das dez respostas dadas pelos/as depoentes o fator tempo figura como elemento importante para a escolha do boxe na academia pesquisada. Isso ratifica a constatação de vários autores de que o tempo representa uma variável significativa para a adesão da prática, pari passu sua falta incide no desligamento da mesma (Telles et al., 2016).

A saúde surge como terceiro aspecto. Nota-se que a maioria dos/as alunos/as entrevistados/as se preocupa com a manutenção da saúde por intermédio da prática de exercício. Trata-se de uma conscientização importante, pois segundo a Organização Mundial da Saúde (OMS), a ausência de prática de exercício equivale a um fator primordial para o desencadeamento de doenças como diabetes, câncer e comprometimentos cardiovasculares (Mcardle et al., 2008).

Dito isso, partimos agora para a segunda pergunta referente ao fator adesão. As repostas encontram-se reunidas no quadro sinóptico a seguir.

Quadro 4: Como você conheceu a academia?

\begin{tabular}{|c|l|}
\hline M1 & "Conheci através de propaganda, pois era perto do meu trabalho." \\
\hline M2 & "Já era amigo do André há bastante tempo e ele sempre chamava para vir treinar." \\
\hline M3 & "Eu corria na avenida onde está localizada a academia e decidi fazer uma aula experimental." \\
\hline M4 & "Eu morava perto da academia e decidi começar com um amigo meu, porém só eu continuei." \\
\hline M5 & $\begin{array}{l}\text { "Eu já conhecia o André, pois treinávamos juntos, aí quando soube que ele havia aberto a academia } \\
\text { eu resolvi vir treinar boxe." }\end{array}$ \\
\hline FI & "Através do meu marido, que já fazia boxe aqui e eu decidi acompanhá-lo." \\
\hline F2 & "Por intermédio de uma amiga que conheceu a academia e me chamou para treinar." \\
\hline F3 & "Conheci através de uma amiga que também pratica boxe" \\
\hline F4 & "O meu irmão descobriu a academia e me chamou para fazer." \\
\hline F5 & "Meu namorado faz aula aqui e me incentivou a treinar" \\
\hline
\end{tabular}

Fonte: Elaboração própria dos pesquisadores.

Depreende-se das respostas o fato dos/as entrevistados/as "acessarem" o espaço por intermédio de indicações de familiares e amigos. Ademais se constatou que essas pessoas mais próximas foram os maiores responsáveis por fomentarem o início da prática do boxe, principalmente no caso das mulheres. Trata-se de uma evidência presente no conteúdo narrativo das entrevistadas (F1, F4 e F5) ao recorrerem a termos como: "me chamou”; “decidi acompanhá-lo"; "me incentivou”, entre outros.

Cenário análogo foi verificado por Lopes e Chiapeta (2010) em um estudo cujo objetivo consistiu em averiguar os motivos de adesão e manutenção da prática de atividades físicas regulares, em academias de ginástica da cidade de Ubá- MG. Ao final concluíram que as mulheres são mais afeitas e abertas às influências de amigos e familiares, para iniciar a prática, se comparado aos homens. Apresentando inquietações científicas análogas, a investigação de Tahara et al. (2003) constatou à relevância da família e da mídia para a adesão à prática de atividade física, em detrimento à vontade intrínseca do aluno.

Ainda em relação à adesão, indagou-se quanto aos objetivos da prática pelos sujeitos pesquisados: 
Quadro 5: Qual o seu objetivo ao treinar o Boxe?

\begin{tabular}{|c|l|}
\hline M1 & "Aprimorar as técnicas e ter mais saúde" \\
\hline M2 & "Saúde é meu objetivo" \\
\hline M3 & "Meu objetivo é manter a saúde" \\
\hline M4 & "Inicialmente meu objetivo era perder peso, hoje eu quero melhorar a técnica." \\
\hline M5 & $\begin{array}{l}\text { "Hoje em dia é pra manter a forma e melhorar o condicionamento físico, mas antes eu treinava para } \\
\text { competir, já competi no MMA." }\end{array}$ \\
\hline FI & "Ganhar resistência é meu objetivo" \\
\hline F2 & "Eu treino para manter a forma e ter mais disposição no decorrer do dia" \\
\hline F3 & $\begin{array}{l}\text { "Meu objetivo principal é manter a saúde, pois tenho hipotireoidismo, mas busco também manter a boa } \\
\text { forma física e o bem estar psicológico, já que a doença mexe de forma negativa com esses aspectos." }\end{array}$ \\
\hline F4 & "Aprender a lutar, para defesa pessoal e me sentir mais confortável e segura na rua." \\
\hline F5 & "Eu quero perder peso e ter mais saúde" \\
\hline
\end{tabular}

Fonte: Elaboração própria dos pesquisadores.

No tocante aos objetivos dos alunos e alunas, verificamos algumas respostas relacionadas ao aprimoramento da técnica de luta, seja para defesa pessoal ou competição. Contudo, boa parte dos/as entrevistados/as faz alusão à manutenção da saúde enquanto principal aditamento da prática do boxe. Não se sabe ao certo a concepção de saúde sobre a qual se embasam, conquanto, parece-nos oportuno evocar o entendimento apregoado por Martins (2017), ao definir saúde sob uma perspectiva multifatorial, segundo a qual atuam inúmeros fatores para que o sujeito desfrute de um estado de completo bem-estar físico, mental, social e não somente se encontrar livre de afecções. Trata-se de uma compreensão mais ampla e elaborada da compreensão de um estado pleno de saúde. Conjecturamos, além disso, que alguns depoentes assinalam o entendimento de "saúde" de modo tácito em suas respostas, haja vista quando explicitam a finalidade da prática corporal correlacionada ao condicionamento físico ou o ganho de resistência muscular, por se tratar de aspectos em parte vinculados ao bem-estar físico, social, mental e a minimização de doenças.

Em relação aos aspectos do condicionamento físico, Martins (2017) anota ser a capacidade do corpo pela qual se torna possível resistir a desafios cotidianos compreendendo as capacidades motoras (força, flexibilidade, agilidade, velocidade, potência, equilíbrio, coordenação e resistência). Nesse sentido, o autor esclarece o fato da melhora do condicionamento físico aumentar a resistência física, fortalecer a musculatura, diminuir a frequência cardíaca e a pressão arterial, melhorando, por sua vez, à capacidade respiratória e a oxigenação. De igual modo melhora a coordenação e o equilíbrio, reduzindo o estresse e a ansiedade, com isso aprimora o funcionamento do sistema imunológico e a proteção do organismo contra doenças (Martins, 2017).

No entanto, quando os/as praticantes fazem alusão à questão da redução do peso e a "boa forma", há no interior do teor narrativo pretensões de ordem objetivas e subjetivas. Na esfera objetiva o aumento da massa magra e a diminuição do tecido adiposo poder-se-ão figurar como importantes agentes para combater ou retardar os processos causadores de doenças crônicas, cardiovasculares, câncer, diabetes tipo 2 e cataratas (Mcardle et al., 2008). Com efeito, pode-se inferir que à prática do exercício regular consiste em um fator primordial para o controle e regulação dos processos metabólicos e fisiológicos da gordura corporal (Carnevali Junior \& Lima, 2009; Mcardle et al., 2008). 
Todavia, implicitamente à dimensão objetiva, têm-se os aspectos de subjetivos adscritos aos signos e ideais (culturais) de beleza - fomentados pelas "demandas da silueta" sob a influência da "corpolatria", de acordo com o exposto anteriormente (Bronzatto et al. 2018; Costa, 2004) -, basta ver a idealização na qual um corpo com um menor índice gordura figurar-se-ia como mais saudável, o que nem sempre se traduz efetivamente. Aliás, o culto ao corpo põe em destaque os cuidados muitas vezes excessivos com a saúde, por efeito engendram uma verdadeira hipocondria cultural (Bronzatto et al., 2018).

\subsection{Da aderência à prática do Boxe, segundo a percepção dos/as entrevistados/as}

As narrativas produzidas pelos/as praticantes de boxe durante a coleta de dados, além de evidenciarem os motivos relacionados à adesão, de igual modo revelaram questões sobre a permanência na atividade. Em relação ao termo aderência, Saba (2001) define-o como sendo o ápice da evolução constante rumo à prática de atividade física, razão pela qual ela não ocorre imediatamente após a adesão. Trata-se, portanto, de um processo cadenciado cujo acontecimento ocorre por intermédio de três pilares, a saber: o sentir-se bem, a motivação e a satisfação. Isso resulta na manutenção da atividade por um longo período de tempo, por efeito gera o hábito e a constância dos/as praticantes no desenvolvimento da modalidade com a qual se envolvem.

Em que pese os elementos arrolados pelo autor supracitado, há outras variáveis cujos efeitos incidem na e para a aderência ao exercício físico, em nosso caso, em especial, interessa-nos não o exercício em si, mas sua presença entremeada ao boxe, razão pela qual propusemos cotejar outros aspectos relativos à adesão dessa prática corporal, são eles: a especificidade da modalidade e o papel do método para o ensino do boxe; a disponibilidade de tempo do/a praticante; e a rede de sociabilidades desenvolvida no interior do local investigado. As próximas indagações do estudo procuram averiguar esses aspectos, tal e qual ao conteúdo do quadro a seguir.

Quadro 6: Quais as atividades que você mais gosta? Por quê?

\begin{tabular}{|c|c|}
\hline M1 & "Como eu quero aprimorar a técnica, eu gosto mais do treino específico." \\
\hline M2 & "Gosto de tudo, pois trabalha o corpo inteiro então não tem como dizer o que é melhor." \\
\hline M3 & "Eu gosto de tudo, porque não fica repetitivo, cada dia tem algo diferente." \\
\hline M4 & "Os treinos técnicos, já que é o que eu busco melhorar." \\
\hline M5 & "Eu prefiro a parte específica, de combate, por gostar da luta. Mas o funcional também é muito bom." \\
\hline FI & $\begin{array}{l}\text { "Eu gosto de tudo, o funcional porque proporciona alto gasto calórico e o técnico que é uma coisa que } \\
\text { eu gosto das Artes Marciais." }\end{array}$ \\
\hline F2 & "O treino funcional, porque ganha massa muscular e queima bastante caloria." \\
\hline F3 & $\begin{array}{l}\text { "Eu gosto de todas as atividades que o André propõe, porque eu gosto demais daqui, não consigo } \\
\text { deixar de vir." }\end{array}$ \\
\hline F4 & "Com certeza o específico, com manopla. Por causa do meu objetivo." \\
\hline F5 & "Eu gosto de tudo, porque são atividades prazerosas." \\
\hline
\end{tabular}

Fonte: Elaboração própria dos pesquisadores.

Sobre as preferências dos/as alunos/as por determinadas atividades, verificou-se que possuem relação com os objetivos contidos na prática do boxe. Ou seja, as pessoas buscam aprimorar as técnicas da luta, geralmente preferem atividades mais específicas, como o trabalho com luvas, manoplas, Punching ball e saco de pancadas. Com a utilização desses equipamentos tem- 
se a possibilidade de treinar os golpes e a força aplicada, afora a prática das habilidades técnicas e das capacidades táticas de defesa, tais como: a guarda alta; a esquiva; e o pêndulo. Isso pode ser observado, sobretudo, nas respostas de M1, M5 e F4.

Contudo, o predomínio das respostas faz referência à manutenção da saúde, na qual opera implicitamente os ideais (culturais) de beleza, de acordo com o exposto anteriormente. Além disso, há quem prefira o treinamento funcional, ou mesmo o caso da entrevistada P3, cuja resposta indica o apreço por todas as atividades desenvolvidas nas aulas. Ademais, merece destaque, o entremear do treino específico e do funcional, cujos efeitos proporcionam significativas vantagens, como a melhora das funções cardiovasculares, a mudança na composição corporal, a melhora da coordenação motora e da postura, com isso otimiza às funções corporais que são essenciais para a realização de tarefas cotidianas (Martins, 2017).

Ainda nessa esteira de análises, buscou-se cotejar a dimensão metodológica e sua relação com a aderência ao boxe. Parecido com as seções anteriores, agrupou-se as respostas em um quadro sinóptico, conforme se vê de agora em diante.

Quadro 7: Sobre as aulas, o que você acha da forma com que são organizadas e conduzidas? Como é o acompanhamento do professor?

\begin{tabular}{|c|l|}
\hline M1 & "Eu acho bacana porque não é repetitivo e o acompanhamento é bem feito, muito legal." \\
\hline M2 & "Top demais! O carisma do André impulsiona a gente." \\
\hline M3 & "Eu acho muito bom. O professor motiva a gente e incentiva o tempo todo." \\
\hline M4 & "É genial! Todo dia tem algo diferente e ele conduz muito bem." \\
\hline M5 & $\begin{array}{l}\text { "Muito bom, pois trabalha o boxe de uma forma diferente, não é só para a luta, o treino é ideal também } \\
\text { para quem quer perder peso e manter a forma." }\end{array}$ \\
\hline FI & \begin{tabular}{l} 
"Eu acho tudo ótimo" \\
\hline F2
\end{tabular} $\begin{array}{l}\text { "Acho bom, pelo fato de chegar aqui e o treino já estar montado, sempre com algo diferente e podendo } \\
\text { sanar nossas dúvidas, ele explica direitinho." }\end{array}$ \\
\hline F3 & $\begin{array}{l}\text { "É motivador! Eu gosto do ritmo com que ele conduz as aulas e fora que sempre tem um treino } \\
\text { diferente." }\end{array}$ \\
\hline F4 & $\begin{array}{l}\text { "Excelentes, pois combina a técnica com outros exercícios o que faz com que o treino seja variado. E o } \\
\text { professor está sempre motivando." }\end{array}$ \\
\hline F5 & $\begin{array}{l}\text { "Muito bom, um treino variado e com o professor motivando de uma forma divertida, faz toda } \\
\text { diferença." }\end{array}$ \\
\hline
\end{tabular}

Fonte: Elaboração própria dos pesquisadores.

Em linhas gerais, ao se examinar os relatos pode-se depreender a existência de uma correlação entre os aspectos metodológicos do ensino e a aderência aos treinos, basta ver a recorrência dessa relação nas respostas, com efeito, incidindo nos aspectos motivacionais, seja em razão da diversificação das atividades propostas, seja pela atenção dispensada aos alunos/as, ou mesmo pelo encorajamento externalizado pelo professor de boxe. Parece-nos oportuno esclarecer que, a motivação, divide-se em duas dimensões, a intrínseca - quando a procura pelas atividades advém da satisfação e do prazer individual - e a extrínseca decorrente de fatores ambientais, cuja influência poderá sobrevir de diferentes canais, uma recompensa, quando há um encorajamento, quer do professor, um amigo ou até mesmo de um familiar - . Na maioria das vezes, os fatores motivacionais intrínsecos e extrínsecos encontram-se conectados, haja vista que a motivação, em geral, decorre da interação entre a pessoa e o ambiente (Balbinotti \& Capozzoli, 2008).

No plano mais específico, a dimensão extrínseca da motivação recebeu relevo consideráveis para a aderência à prática do boxe, no contexto investigado. De acordo com as respostas, ficou patente a motivação extrínseca dos/as praticantes, com base na 
intervenção docente, seja em razão do planejar bem os treinos, ou conduzir coerentemente as aulas, seja pelo simples encorajamento endereçado aos aprendizes, ao longo das mesmas. Mesmo porque, o fazer docente consiste em um dos vetores para o processo de motivação da aprendizagem, de acordo com (Tapia \& Fita, 2003)

Outra especificidade que recebera destaque, diz respeito à diversificação das atividades, o que para Lussac (2008) significa que quanto maior a diversificação das atividades, melhores serão as possibilidades dos praticantes atingirem o desempenho ideal. À face do exposto, pode-se inferir que a motivação e a diversidade de conteúdos possuem uma relação direta com a aderência ao boxe, de tal modo que identificamos essa interface nas respostas das depoentes F2, F3, F4 e F5. Ademais, de acordo com o autor supracitado, o planejamento do professor fomentando a diversificação de atividades, mitiga o risco do efeito platô - refere-se ao estado de adaptação ao ponto de estagnar o processo de desenvolvimento do organismo em treinamento - e de fatores desestimulantes, com efeito, atuando diretamente na motivação (extrínseca). Para tanto, considera-se à criatividade o baluarte para se fomentar a variabilidade pedagógica (Lussac, 2008).

Pois bem, para além da diversificação pedagógica, conjecturou-se que a disponibilidade de horários para a prática do boxe figurar-se-ia na qualidade de uma variável fundamental para a aderência. Em razão disso indagou-se os/as pesquisados/as a esse respeito, estando às respostas contidas no quadro daqui em diante.

Quadro 8: De que maneira a disponibilidade de horários atende a conciliação da atividade com a vida cotidiana?

\begin{tabular}{|c|l|}
\hline M1 & "Ajuda bastante, principalmente pra quem trabalha ou estuda é benéfico." \\
\hline M2 & $\begin{array}{l}\text { "O fato de não ter aquele horário engessado para o treino facilita muito, principalmente nos dias mais } \\
\text { corridos. Não tem desculpa para não fazer." }\end{array}$ \\
\hline M3 & $\begin{array}{l}\text { "Faz muita diferença, às vezes você está muito cansado para vir à noite, porém há aulas pela manhã, em } \\
\text { razão disso é possível treinar mais cedo, como resultado fica-se bem o dia todo." }\end{array}$ \\
\hline M4 & $\begin{array}{l}\text { "É super favorável! Seria impossível atender a um grande numero de alunos, como tem aqui, se tivessem } \\
\text { poucos horários." }\end{array}$ \\
\hline M5 & \begin{tabular}{l} 
"Faz diferença! Sempre que há um tempo vago consigo vir treinar." \\
\hline FI
\end{tabular} $\begin{array}{l}\text { "Facilita, eu venho quase sempre no mesmo horário, mas se por algum motivo eu não puder, posso vir em } \\
\text { outra aula." }\end{array}$ \\
\hline F2 & $\begin{array}{l}\text { "No meu caso não influencia, pois venho sempre no mesmo horário, mas sei que para outras pessoas faz } \\
\text { diferença." }\end{array}$ \\
\hline F3 & "A flexibilidade de horários faz total diferença." \\
\hline F4 & "Faz toda diferença, foi um dos atrativos quando eu fiz a matrícula, achei um diferencial." \\
\hline F5 & "Atende-me muito bem, principalmente em semanas de prova ou quando surge algum imprevisto." \\
\hline
\end{tabular}

Fonte: Elaboração própria dos pesquisadores.

Em relação à disponibilidade de horários, a maioria dos/as entrevistados/as reconheceram que o fato da academia oportunizar diversas aulas ao longo do dia, faculta coadunar a prática de atividade física regular com a vida cotidiana e laboral. A literatura especializada indica a ausência de tempo como o principal fator de desistência da realização de exercício. Quanto a isso, Santos e Knijnik (2006) admitem que essa questão esteja relacionada, principalmente, com a jornada excessiva de trabalho, uma vez que é difícil conciliar as obrigações familiares, a prática de exercício e a vida profissional. De igual modo, Sombrio (2016) ressalta que a não consecução de exercício físico ou a sua desistência ocorre, sobretudo, pela dificuldade em coligar a prática com a rotina diária.

Ora, de nada adiantaria a academia oferecer um repertório amplo de horários se as relações sociais estabelecidas em seu 
interior não conferem experiências de convívio significativas. Cientes da relevância da rede de sociabilidades para a adesão e aderência à prática do boxe, - até porque já discorremos anteriormente, quanto aos aspectos motivacionais (internos e externos) envolvendo as interações entre pessoas (professor, amigo, familiar, etc.) e o ambiente - cujas implicações afetam tanto o ingresso quanto a permanência nessa prática corporal, interrogou-se os/as depoentes em relação às interações estabelecidas na esfera da academia. Vejamos os relatos doravante.

Quadro 9: Como é a relação entre os praticantes e as interações que ocorrem dentro da academia?

\begin{tabular}{|c|c|}
\hline M1 & $\begin{array}{l}\text { "A relação é bacana, a própria aula faz você interagir com os demais, não tem aquela } \\
\text { individualidade como na academia de musculação, por exemplo." }\end{array}$ \\
\hline M2 & "É uma relação boa e muito tranquila." \\
\hline M3 & $\begin{array}{l}\text { "Eu acho a relação muito boa, um ambiente familiar, no qual todo mundo encontra-se muito } \\
\text { unido." }\end{array}$ \\
\hline M4 & $\begin{array}{l}\text { "A socialização é totalmente amigável, raramente encontramos isso em academias, a galera é muito } \\
\text { unida, tem total respeito e se trata como família." }\end{array}$ \\
\hline M5 & "Muito bacana, se não tivesse essa interação, acho que o treino não ficaria legal." \\
\hline FI & $\begin{array}{l}\text { "Eu acho bem legal, o próprio treino favorece, às vezes por serem realizados em dupla, possibilita } \\
\text { conhecer gente nova e fazer novas amizades." }\end{array}$ \\
\hline F2 & $\begin{array}{l}\text { "É bem legal! Diferente de outras academias, aqui o pessoal interage bastante. No meu caso fez } \\
\text { total diferença, pois sempre fui muito tímida e hoje consigo interagir melhor com outras pessoas." }\end{array}$ \\
\hline F3 & $\begin{array}{l}\text { "Eu gosto muito, dado que aqui somos todos iguais, independente de profissão ou gênero. Somos } \\
\text { muito respeitados e acolhidos." }\end{array}$ \\
\hline F4 & $\begin{array}{l}\text { "Assemelha-se a uma família, fazemos amizades, comemoramos aniversários e até sentimos falta } \\
\text { quando alguém não vem." }\end{array}$ \\
\hline F5 & "Acho ótimo, pior coisa é treinar em um ambiente em que ninguém interage." \\
\hline
\end{tabular}

Fonte: Elaboração própria dos pesquisadores.

Constata-se a partir dos relatos, um consenso quanto à qualidade das interações sociais constituídas no interior da academia investigada, ao ponto da entrevistada F4 compará-la ao nível de relações familiares, dimensão que sobrepuja a esfera do convívio apenas, adentrando o domínio do pertencimento e de identificação afetiva, algo não tão simples de ser desenvolvido, vale salientar. A esse respeito, Sombrio (2016) anota que a construção da identidade resulta da interação social, visto que implica na pessoa se reconhecer como membro de um grupo e não se ver sozinha ou isolada, mas coexistindo com outras pessoas. Tratase de um nível de interação cujos efeitos interferem na formação dos indivíduos e isso se reflete no ambiente, à medida que as pessoas se sentem pertencentes a um grupo, por efeito buscam melhorias para o espaço pelo qual interagem (Sombrio, 2016).

Ademais, a rede de sociabilidade pode operar na qualidade de um importante vetor para a adesão, ou para permeância da prática corporal, dado que o pertencimento a um grupo pode atrair outros indivíduos, pari passu conservá-los naquela atividade, haja vista as narrativas de M1, F2 e F5, cujo teor demonstra que a sociabilidade concerne num elemento fundamental. Em última análise, tem-se na qualidade das interações sociais constituídas no espaço prospectado, um fator sine qua non para a adesão e aderência ao boxe. Verdade seja dita, alguns relatos exprimem profundo incômodo com academias em que os exercícios ocorrem de modo isolado, com pouca ou nenhuma interação social, consoante à percepção de M1 e F5.

\section{Conclusão}

A investigação empreendida procurou identificar as razões que conduzem as pessoas a se inserirem e se conservarem praticando o boxe. Em outros termos, o estudo desenvolvido perscrutou os fatores responsáveis pela adesão e a aderência dessa 
prática corporal, numa academia situada ao Sul do estado de Minas Gerais/MG. A partir dos dados examinados, pode-se constatar a existência de algumas variáveis as quais afetam à prática dessa manifestação corporal, conquanto, algumas se correlacionam e se realçam segundo as percepções dos/as envolvidos/as.

No que tange à adesão, entre os elementos cotejados pelo estudo, destacam-se: 1- Saúde, visto que muitos aprendizes começaram a praticar o boxe alvitrando manter ou melhorar a saúde, dispor de mais disposição, melhorar condicionamento físico e perder peso, a despeito de não se ter clareza quanto ao entendimento do conceito de saúde apresentado pelos/as participantes; 2Disponibilidade de horários, dado ao fato de figurar como principal motivo da desistência da prática do boxe, evento já retratado pela literatura especializada e ratificado por nossa investigação; 3- A paixão pelo boxe e o anseio por aprimorar as habilidades técnicas da luta para os mais variados fins; 4- Encorajamento encontrado tanto na família quanto entre amigos, aliás, os principais responsáveis por apresentar o espaço aos praticantes.

Em relação à aderência os fatores aludidos com frequência foram os seguintes: 1- A motivação, com destaque a dimensão extrínseca; 2 - A diversificação das atividades, uma vez que aumentam as possibilidades dos praticantes atingirem o desempenho corporal esperado, com destaque ao planejamento dos treinos, ou pela condução coerente e alentadora das aulas; 3A disponibilidade de horários fornecida pela academia, uma constatação majoritária entre os/as pesquisados/as, em virtude de oportunizar a conciliação entre a prática de atividade física regular, a vida cotidiana e a laboral; 4 - A rede de sociabilidade, por certo a grande descoberta do estudo, já que os relatos indicaram expressiva relevância nas interações sociais engendradas no interior da academia investigada, com efeito, adentrando o domínio do pertencimento e da identificação afetiva, sendo um importante vetor para a adesão, ou para permeância da prática corporal em questão.

Por fim, espera-se que malgrado a pesquisa apresente limites - especialmente em razão da reduzida amostragem de entrevistados, todavia coerente sob a acepção qualitativa - possa lançar luz sobre o fenômeno em perspectiva (lê-se a adesão e aderência ao boxe), por efeito, suscite novas investigações, pelas quais seja possível explorar e aprofundar as noções de saúde apresentada pelos praticantes, de igual modo identificar variáveis (objetivas e subjetivas), que desvelem o modus operandi das redes de sociabilidades, em outros contextos. Quiçá mapear circunstâncias cujas implicações venham a dissuadir o ingresso, ou mesmo a continuidade à prática do boxe, em especial, desvelando a maneira de agir das "demandas da silueta" enleadas em enunciados sob a égide da saúde, quando, na prática, os cuidados excessivos se resumem em uma espécie de "ditadura da beleza", produzindo, por sua vez, um efeito antagônico ao bem-estar (Bronzatto et al. 2018). Não nos esqueçamos da advertência de Santin (1987), os componentes intencionais externos do corpo (emagrecimento, definição muscular, ampliação das capacidades motoras, dentre outros) não podem estar desarticulados dos componentes intencionais internos (a alegria, o prazer, a inteireza inerente ao próprio fato de se movimentar), senão a experiência corpórea incorrer-se-ia no escamoteamento dos modos de ser e estar no mundo.

\section{Referências}

Balbinotti, M. A. A., \& Capozzoli, C. J. (2008). Motivação à prática regular de atividade física: um estudo exploratório com praticantes em academias de ginástica. Revista Brasileira de Educação Física e Esporte. 22(1), 63-80.

Bronzatto, M., Oliveira, A. J., Camargo, R. L., \& Carneiro, K. T. (2018). As demandas contemporâneas da silhueta - o empobrecimento da expressão corporal e a necessidade de formar corpos éticos. In: J. Gomes (Org.). Combate à erotização e ao abuso sexual infantil: novas propostas. CRV.

Carnevali Junior, L. C., \& Lima, W. P. (2009). Lipídios, expressão gênica e exercício. In: W. P. Lima (Org). Lipídios e Exercício, aspectos fisiológicos e do treinamento. Phorte.

Caruzzo, A. M., Contreira, A. R., Caruzzo, N. M., Ribas, M. L., Lima, A. M. de, Codonhato, R., \& Fiorese, L. (2020). Passion in sport: a systematic review in the context of individual modalities. Research, Society and Development, 9(8), e186985513. https://doi.org/10.33448/rsd-v9i8.5513

Costa, J. F. (2004) O vestígio e a aura: corpo e consumismo na moral do espetáculo. Garamond.

Gomes, R. A Análise de Dados em Pesquisa Qualitativa (2010). In: M. C. S. Minayo (org), S. F. Deslandes, O. C. Neto, \& R. Gomes. Pesquisa Social: Teoria, 
Research, Society and Development, v. 10, n. 5, e50510515217, 2021

(CC BY 4.0) | ISSN 2525-3409 | DOI: http://dx.doi.org/10.33448/rsd-v10i5.15217

Método, e Criatividade. Vozes.

Lopes, V. M. B. S., \& Chiapeta, S. M. S. V. (2010). Motivos de adesão e manutenção da prática de atividades físicas regulares em academias de ginástica da cidade de Ubá, MG. Lecturas: Educación Física y Deportes. 15, 143-151.

Lüdke, H. A. M., \& André, M. (1986). Pesquisa em educação: abordagens qualitativas. EPU.

Lussac, R. M. P. (2008). Os princípios do treinamento esportivo: conceitos, definições, possíveis aplicações e um possível novo olhar. EFDeportes. 13, 121-130.

Mcardle, W. D., Katch, F. I., \& Katch, V. I. (2008) Fisiologia do Exercício - Energia, Nutrição e Desempenho Humano. Guanabara Koogan.

Martins, G. R. S. M. (2017). Adesão e aderência à iniciação de atividades físicas em academias de musculação. Med.

Melo V. A., \& Vaz A. F. (2006). Cinema, corpo, boxe: suas relações e a construção da masculinidade. ArtCultura. 8(12), 139-160.

Pereira, Á. S., Carneiro, K. T., Reis, F. P. G., \& Scaglia, A. J. (2021). Pedagogia das lutas/artes marciais: do ambiente de jogo à sistematização do ensino. Brazil Publishing.

Reis, R. A. M. dos, Oliveira, V. M. de ., Badaró, L. F. ., Mattes, V. V. ., Menegaldo, P. H. I. ., Souza, N. B. da S., Brasil, M. R., Souza, J. de ., \& Herold Junior, C. . (2020). The martial arts between sport and education: an analysis from Taekwondo. Research, Society and Development,9(11), e93891110600. https://doi.org/10.33448/rsd-v9i11.10600

Saba, F. (2001). Aderência. Manole Ltda.

Sampieri, R. H., Collado, C. F., \& Lucio, M. P. B. (2013). Metodologia de Pesquisa. Penso.

Santin, S. (1987). Reflexões antropológicas sobre a educação física e o esporte escolar. In: Santin, S. Educação fisica: uma abordagem filosófica da corporeidade. Ijuí: Unijuí Editora, p. 39-52.

Santos, S. C., \& Knijinik J. D. (2006). Motivos de Adesão à prática de atividade física na vida adulta intermediária. Revista Mackenzie de Educação Física e Esporte. 5, 23-34.

Silva, B. B. P. O., Cavichiolli, F. R., \& Capraro A. M. (2015). Adesão e permanência de mulheres no boxe em Curitiba- PR. Motrivivência. 27(45), 123-136.

Sombrio, D. A. (2016). Motivos de adesão e aderência a prática de exercício físico do clientelaluno de personal trainer no município de Criciúma. (Trabalho de Conclusão de Curso). Universidade do Extremo Sul Catarinense- Unesc.

Tahara, A. K., Schwartz, G. M., \& Silva, K. A. (2003). Aderência e manutenção da prática de exercícios em academias. Revista Brasileira Ciência e Movimento. 11(4), 7-12.

Tapia, J. A. (2003). Contexto, motivação e aprendizagem. In: J. A. Tapia, \& E. C. Fita. A motivação em sala de aula: O que é, como se faz. Loyola.

Telles, T. C. B., Araruna, L.C., Almeida, M. S., \& Melo, A. K. (2016). Adesão e aderência ao exercício: um estudo bibliográfico. Revista Brasileira de Psicologia do Esporte. 7(3), 13-25. 